\title{
The Need for Open Science
}

\author{
Noorsaadah Abd. Rahman ${ }^{1, *}$ \\ ${ }^{1}$ Deputy Vice-Chancellor (Research \& Innovation)'s Office, University of Malaya, 50603 Kuala Lumpur, Malaysia
}

\section{${ }^{*}$ Corresponding author email: noorsaadah@um.edu.my}

Received date: 21 Aug 2019

Published date: 31 Dec 2019

\section{How to cite:}

Abd Rahman, N. (2019). The Need

for Open Science. Journal of

Research Management \&

Governance, 2(1), 22-30.

Retrieved from https://

ejournal.um.edu.my/index.php/

JRMG/article/view/19517

\begin{abstract}
Open Science is about sharing knowledge where research data and its underlying methods and processes are made available "freely" for reuse, redistribution and reproduction by those other than the researchers themselves. The availability of these data publicly should promote the translation of research output into innovation and new technologies. In addition, making research data and knowledge publicly available to others would help to build trust on the research findings and could support public policies and further investments.
\end{abstract}

Keywords: Open Science; Open Access; Open Platform

DOI:

https://doi.org/10.22452/

jrmg.vol2no1.3

\section{Introduction}

Scientific advancement has led to the economic, technology and societal progress of humanity. Many scientific discoveries and innovation such as vaccination for polio and invention of mobile phones have resulted in better life for humankind. The pace of science and its discovery is moving very fast with the advancement of modern science and technology. Particularly, computer and internet-of-things has enabled a vast number of scientific and research reports being published annually. However, most of these reports are not properly verified resulting in many non-reproducible results and data. For example, in an independent attempt to replicate selected results from a number of "high-profile" papers in Cancer Biology, researchers could replicate only 40 percent or less of the results reported (Davis et al., 2014). In a report in Nature Reviews Drug Discovery, Prinz and his co-workers questioned the reliability of published data on potential drug targets (Prinz and Asadullah, 2011). This "reproducibility crisis" has led many scientists to push for ways to improve scientific reporting to increase reliability. One way to do this is through "open science".

Open Science means that not just the scientists, but teachers, policymakers, journalists and other nonscientists, would have access to the research data and materials. Since most research is funded through public funds and tax-payers money, allowing anyone access to study these data would increase the value of every penny invested (Nielsen, 2011).

One of the earliest well-known examples of Open Science is the Human Genome Project which started in 1990 (Hood and Rowen, 2013). Throughout the course of the project, the scientific community widely 
shared the data on the human genome. In order to encourage optimal collaboration, they also kept a moratorium on publishing. Open Science has enabled the scientists involved to decode the human genome in less than 15 years. In another example of Open Science, "brain-sourced" research, Tim Gowers, a mathematician at Cambridge University started the Polymath Project where he took an unsolved mathematical problem, published it in his scientific blog and invited everyone to contribute in solving the problem (Polymath Projects, 2019). On-line contributors were able to solve not just Gower's original problem, but also harder problem that was included the original as a specific example in only 37 days after the start of the project.

European Union has funded several initiatives which have led to steady progress towards Open Science (Beagrie and Houghton, 2016). One good example is the 'European Lead Factory' project under the Innovative Medicines Initiative (IMI) (European Commission, 2019). In this project, academic and industry partners pooled together around half a million compounds (chemical molecules) which are made publicly and freely available in a repository to any scientist who wants to screen and validate potential new drug targets.

The ecosystem underpinning Open Science which began with the World Wide Web or WWW is evolving rapidly. There are many social network platforms available for scientists and researchers to use and validate research data in a "brain-sourced" way (Nielsen, 2011; Nielsen, 2012; Vignoli et al., 2014; Crouzier, 2015). Several platforms, which are available for open access for scholarly publications to facilitate Open Science eco-system, are shown in the Table 1.

Table 1: Some Platform for Scholarly Publications for Open Science.

\begin{tabular}{|c|l|}
\hline Academia.edu & $\begin{array}{l}\text { A US-based platform for sharing of research papers. Academic.edu } \\
\text { monitors the impact of these research and tracks the research of } \\
\text { academics they follow. More than } 30 \text { million academics are signed up } \\
\text { to the site by January 2016. A recent study reported that papers up- } \\
\text { loaded to Academia.edu receive a 73\% boost in citations over five } \\
\text { years. }\end{array}$ \\
\hline Research Gate & $\begin{array}{l}\text { This is a platform based in Berlin with virtually similar functions to } \\
\text { Academia.edu and had about } 8 \text { million user and } 80 \text { million publica- } \\
\text { tions in January 2016. Research Gate generates a Research Impact } \\
\text { Factor for the uploaded documents of researchers, based on factors } \\
\text { such as 'classical' citations and on the number of downloads by other } \\
\text { users. }\end{array}$ \\
\hline Mendeley & $\begin{array}{l}\text { An Amsterdam-based reference manager owned by the Elsevier pub- } \\
\text { lishing company has around 3 million users (June 2014). Mendeley } \\
\text { allows for open annotation and generation of bibliographies. }\end{array}$ \\
\hline Figshare & $\begin{array}{l}\text { An online digital repository supported by Digital Science (a division of } \\
\text { Macmillan Publishers). In Figshare, researchers can make their re- } \\
\text { search outputs available in a citable, shareable and discoverable } \\
\text { manner, including figures, datasets, images and videos. }\end{array}$ \\
\hline
\end{tabular}




\begin{tabular}{l|l} 
F1000Research & $\begin{array}{l}\text { This is an Open Science publishing platform for life scientists which } \\
\text { offers immediate publication without editorial bias and publishes all } \\
\text { scientific research within a few days. F1000Research uses an author- } \\
\text { led process with open, invited peer review of articles conducted fol- } \\
\text { lowing publication of the research work. It focuses on scientific } \\
\text { soundness rather than novelty or impact and all published research } \\
\text { articles must be accompanied by the data on which the reported re- } \\
\text { sults are based. This is critical to enable reanalysis; replication } \\
\text { attempts and data reuse. }\end{array}$ \\
\hline
\end{tabular}

There are currently numerous data repositories worldwide to support Open Science. These repositories may be called data centers, data archives, or scientific databases and are often divided into three categories:

i) Institutional Repositories (IRs) are affiliated with an institution such as the Digital Repository (DRNTU) at Nanyang Technological University, Singapore.

ii) Domain-specific or Disciplinary Repositories (DRs) are discipline-specific and usually operated by a professional organization, a consortium of researchers, or a similar group.

iii) General-purpose or Open Repositories (ORs) which allow researchers to deposit and make their data available regardless of disciplinary or institutional affiliation. Some examples of this category of repositories are listed in Table 2.

Table 2: Examples of General-purpose Data Repositories Supporting Open Science

\begin{tabular}{|l|l|}
\hline Zenodo (Zenodo, 2019) & $\begin{array}{l}\text { This platform was created in 2013 by OpenAIRE and CERN } \\
\text { as an all-purpose, open repository for all scholarship, ena- } \\
\text { bling researchers from all disciplines to deposit publica- } \\
\text { tions, datasets and other research artifacts such as code, } \\
\text { posters, presentations and share their research outputs, } \\
\text { regardless of size or format. Free to upload and free to } \\
\text { access for researchers to upload files up to 50 GB. }\end{array}$ \\
\hline $\begin{array}{l}\text { The Australian Research Data } \\
\text { Commons (ARDC) (Australian } \\
\text { Research Data Commons, }\end{array}$ & $\begin{array}{l}\text { The Australian Research Data Commons (ARDC) was } \\
\text { formed on 1 July 2018 which is an initiative that enables } \\
\text { Australian research community and industry access to } \\
\text { nationally significant, leading edge data intensive e- } \\
\text { Infrastructure, platforms, skills and collections of high- } \\
\text { quality data. ARDC provides high capacity digital data stor- } \\
\text { age for nationally significant collections, cloud computing, } \\
\text { collection curation and data management resources, as } \\
\text { research-data-australia/ } \\
\text { well as national catalogue, identifier and vocabulary ser- } \\
\text { vices. }\end{array}$ \\
\hline $\begin{array}{l}\text { OSF (Center for Open Sci- } \\
\text { ence, 2019; OSF, 2019) }\end{array}$ & $\begin{array}{l}\text { OSF is a free, open platform to support research and ena- } \\
\text { ble collaboration developed by Center for Open Science } \\
\text { (CoS) whose mission is to increase openness, integrity, } \\
\text { and reproducibility of research. }\end{array}$ \\
https://osf.io/ \\
https://cos.io/
\end{tabular}




\begin{tabular}{|c|c|}
\hline $\begin{array}{l}\text { European Data Portal } \\
\text { (European Data Portal, 2019) } \\
\text { https:// } \\
\text { www.europeandataportal.eu } \\
\text { /en/resources/training- } \\
\text { companion/open-data- } \\
\text { platforms }\end{array}$ & $\begin{array}{l}\text { The strategic objective of the European Data Portal is to } \\
\text { improve the accessibility and increase the value of Open } \\
\text { Data. This portal also enables metadata of Public Sector } \\
\text { Information available on the public data portals across } \\
\text { European countries to be harvested. }\end{array}$ \\
\hline $\begin{array}{l}\text { Open Research Data Platform } \\
\text { Switzerland - ORD@CH (ETH } \\
\text { Zürich, 2019) } \\
\text { https://sis.id.ethz.ch/ } \\
\text { researchdatamanagement/ } \\
\text { service-ordch.html }\end{array}$ & $\begin{array}{l}\text { ETH Scientific IT Services with collaboration of partners } \\
\text { from academia and industry has developed a publication } \\
\text { platform for open research data in Switzerland } \\
\text { (ORD@CH), based on the open-source data publication } \\
\text { system, CKAN. This platform has been made as a perma- } \\
\text { nent infrastructure for sharing open research data in Swit- } \\
\text { zerland since } 2016 \text {. The ORD@CH platform provides a } \\
\text { meta-data catalog for the publication of research data } \\
\text { from life sciences, social sciences as well as humanities } \\
\text { and other domains. }\end{array}$ \\
\hline $\begin{array}{l}\text { Peking University Open Re- } \\
\text { search Data Platform (Peking } \\
\text { University Open Research } \\
\text { Data, 2019) } \\
\text { https:// } \\
\text { opendata.pku.edu.cn/ }\end{array}$ & $\begin{array}{l}\text { The Peking University Open Research Data Platform was } \\
\text { developed based on the "standardization of property } \\
\text { rights protection" and with the purpose of "advocating } \\
\text { open science" by promoting openness, exchanging, and } \\
\text { sharing of research data. This platform provides research- } \\
\text { ers with the management, release, and storage services of } \\
\text { research data, encourages researchers to open and share } \\
\text { data, and provides data users with browsing, retrieval, } \\
\text { and download services for research data, and promotes } \\
\text { the dissemination, reuse, and standardization of research } \\
\text { data. }\end{array}$ \\
\hline
\end{tabular}

\section{Several Global Initiatives of Open Science Policies}

On 22nd October 2003, The Berlin Declaration on Open Access to Knowledge in the Sciences and Humanities were launched (Max-Planck-Gesellschaft, 2019). This Declaration asserted that scholarly research results and cultural heritage shall be freely accessible and usable for scientists and the public. Fundamental to the declaration is that Open Access (OA) is a responsibility of research performing organisations and research funding organisations, and that the publication and dissemination of research results are integral parts of the research process. Following this declaration, several initiatives on Open Access and Open Science were carried out by various communities and nationals around the world. A brief description of some of the initiatives are described below.

\subsection{The G8 Community (G8 UK, 2013)}

In June 2013, the G8 Science Ministers met in London approved of a statement which proposed the consideration of new areas for collaboration and agreement on global challenges, global research infrastructure, open scientific research data, and increasing access to the peer-reviewed, published results of scientific research. In order to address global challenges and maximise the social and economic 
benefits of scientific research, the G8 Science Ministers support the set of principles for open scientific research data which included publicly funded scientific research data to be opened with fewest constraints as possible; open scientific research data should be easily discoverable, accessible, assessable, intelligible, useable, and interoperable to specific quality standards, where possible and to maximise the value that can be realised from the research data. To ensure that open scientific research data principles will be adopted by the scientific communities, the G8 Science Ministers agreed for need of an appropriate policy environment to underpin the Open Science initiative.

\subsection{CODATA (CODATA, 2019)}

CODATA is an interdisciplinary Committee on Data for Science and Technology of the International Science Council (ISC) established in 1996. Amongst its role is to promote global collaboration to advance Open Science and to improve the availability and usability of data for all areas of research. CODATA supports the principle that research data should be available and "open as possible and as closed as necessary". CODATA advocates for these data to follow the FAIR (Findable, Accessible, Interoperable and Reusable) principles. In its Prospectus of Strategy and Achievement 2016, CODATA has identified three priority areas in their Open Science initiative which are:

i) to promote principles, policies and practices for Open Data and Open Science;

ii) to advance the frontiers of data science;

iii) to build capacity for Open Science needed to support open data.

2.3 Japan (Global Perspectives Cabinet Office Japan, 2015; Research Center for Open Science and Data Platform, 2019)

Japan Science and Technology Agency (JST) established an Open Access policy on research publication and research data management known as the JST Open Access Policy in 2013. The policy defines JST's stand on Open Access to research publications and management of research data resulting from research projects funded by JST and researchers who participate in projects awarded by JST are required to handle research results appropriately complying with this policy. This policy was recently replaced by the JST Open Science Policy.

2.4 Australia (Houghton et al., 2009; Mizera, 2013; Australasian Open Access Strategy Group, 2019) In January 2013, the Australian Government enacted a policy on Open Access. Under this new policy, all the results of research conducted with the financial support of the Australian Research Council (ARC) must be published in an Open Access model within 12 months of publication and that these materials should be published in specific institutional repositories. As stated in the ARC's website:

"The overarching aim of ARC's Policy is to ensure that the findings of publicly funded research are made available to the wider public as soon as possible. Both the research community and the public gain from knowledge derived from ARC funded research, and both wish to derive maximum benefit from these outputs."

2.5 China (Markin, 2018; Li and Zhang, 2019)

In May 2014, the Chinese Academy of Sciences published its Open Access policy calling for the free accessibility of publicly funded research results in the form of academic articles. In doing this, 
researchers are encouraged to adopt the Green or Hybrid Open Access in the framework of which scientific papers enter Open Access 12 months after their publication.

In October 2017, China joined the global OA2020 initiative that aims to accelerate the transition to Open Access around the world. Leading scientific institutions of China, such as the Chinese Academy of Sciences (CAS), China's National Science Library and National Science and Technology Library, have affirmed the importance of Open Access for scientific research and communication.

In May 15, 2018, the National Natural Science Foundation of China (NNSFC), which supports basic science, and CAS, a body that provides research funding for over 100 scientific institutions in China issued a policy statement on Open Access, mandating that research results of the projects they fund should be made openly accessible within 12 months of their publication.

2.6 United States of America (National Institutes of Health, 2003; Nielsen, 2011; Noorden, 2013)

Since 2008, the US National Institutes of Health (NIH) has required research to be publicly accessible after 12 months. However, this new policy does not insist that every agency copies the NIH approach exactly. In 2012, John Holdren, the director of the White House office of science and technology policy (OSTP), told federal agencies to prepare plans to make their research results free to read within 12 months after publication following a petition urging the president to require free access to scientific journal articles from publicly funded research. In February 2013, the US government announced its Open Access policy which mandated all publications arising from taxpayer-funded research to be made free to read after a one-year embargo period.

2.7 European Commission Initiative (Ramjoué, 2015; European Commission, 2017; European Open Science Cloud, 2017; European Open Science Cloud, 2019)

The European Commission has taken a big step towards open science in Europe and is probably the most matured initiative. For the European Commission, open science provides the context for open access to publications and open research data. Since 2008, the European Commission has been running the Open Access Pilot in their FP7 programmes. Currently, all projects receiving Horizon 2020 funding are required to ensure that any peer-reviewed journal article they publish is openly accessible and free of charge. In 2016, European Commission went one step further by launching the European Open Science Cloud (EOSC). EOSC is an initiative to build a competitive data and knowledge economy in Europe. At the first EODC Summit in June 2017, the EOSC Declaration was endorsed by more than 70 institutions.

\subsection{Singapore (Ooi, 2017; UNESCO, 2017)}

Closer to home, Singapore contributes to the world of Open Access (OA) in the form of Institutional Repositories in some of the well-known Institutions in Singapore. As of May 2015, there are 3 OA repositories from Singapore registered in the Registry of Open Access Repositories (ROARMAP). They are "Institutional Knowledge" at Singapore Management University, "Scholar Bank" at National University of Singapore and "Digital Repository (DR-NTU)" at Nanyang Technological University. As of July 2014, the Singapore's National Research Foundation (NRF) requires research-performing institutions to have Open Access policies in order for researchers to access their grants. 
2.9 Malaysia (Akademi Sains Malaysia, 2019)

Malaysia does not yet have an open science policy. However, recently, the Ministry of Energy, Science, Technology, Environment and Climate Change (MESTECC) and the Academy of Sciences Malaysia (ASM) launched the Malaysia Open Science Platform (MOSP) initiative. MOSP is to be a trusted data-sharing platform that enables accessibility and sharing of research data aligned with the national priorities and international best practices to strengthen science, technology and innovation (STI) collaborative ecosystem for Malaysia. The first phase of this initiative is aimed at connecting research data, researches and publication between five research universities, and 15 MESTECC research institutes and agencies.

\section{Summary}

Open science is a movement to make scientific research, data, and dissemination accessible to all levels of an inquiring society, amateur or professional. This includes open access to the outputs of scientific research, such as data and publications. It also provides opportunities for citizen science where the public can voluntarily participate voluntarily in the research process, thus enabling real-world problems to be addressed.

Open Science is about sharing knowledge as early as practically possible in the discovery process' which may lead to a boost in innovation. It does not, however, mean 'free science'. It is therefore essential to ensure that intellectual property is protected before making knowledge publicly available to others that would translate research output into innovation and new technologies.

\section{References:}

Akademi Sains Malaysia. (2019). Malaysian Collaborative Network Platform for Disruptive Innovation (ICONNECT) \& Malaysia Open Science Platform (MOSP) Initiatives. Retrieved from https:// www.akademisains.gov.my/initiatives/i-connect-mosp/

Australasian Open Access Strategy Group. (2019). Open access in Australia. Retrieved from https:// aoasg.org.au/open-access-policies/

Australian Research Data Commons. (2019). Research Data Australia. Retrieved from https:// ardc.edu.au/services/research-data-australia/

Beagrie, N. \& Houghton, J. (2016). The Value and Impact of the European Bioinformatics Institute. EMBL -EBI. Retrieved from https://beagrie.com/static/resource/EBI-impact-summary.pdf

Center for Open Science. (2019). Center for Open Science Homepage. Retrieved from https://cos.io/

CODATA. (2019). The Beijing declaration on research data. Retrieved from http://www.codata.org/ uploads/Beijing\%20Declaration-19-11-07-FINAL.pdf

Crouzier, T. (2015). Science Ecosystem 2.0: how will change occur? Luxembourg: European Union. Retrieved from https://ec.europa.eu/research/innovation-union/pdf/expert-groups/rise/ science ecosystem 2.0-how will change occur crouzier 072015.pdf

Davis, R.J., et al. (2014, December 10). Reproducibility Project: Cancer Biology. Retrieved from https:// elifesciences.org/collections/9b1e83d1/reproducibility-project-cancer-biology

ETH Zürich. (2019). Open Research Data Platform Switzerland - ORD@CH. Retrieved from https:// sis.id.ethz.ch/researchdatamanagement/service-ordch.html

European Commission. (2017). H2020 Programme: Guidelines to the rules on open access to scientific publications and open access to research data in Horizon 2020. Retrieved from https:// ec.europa.eu/research/participants/data/ref/h2020/grants manual/hi/oa pilot/h2020-hi-oa-pilotguide en.pdf 
European Commission. (2019). European Lead Factory. Retrieved from https://cordis.europa.eu/ project/id/115489

European Data Portal. (2019). Open Data Platforms. Retrieved from https:// www.europeandataportal.eu/en/resources/training-companion/open-data-platforms

European Open Science Cloud. (2019). EC Documents. Retrieved from https://www.eosc-portal.eu/ policy/ec-documents

European Open Science Cloud. (2017). EOSC Declaration. Retrieved from https://ec.europa.eu/ research/openscience/pdf/eosc declaration.pdf

Global Perspectives Cabinet Office Japan. (2015). Promoting Open Science in Japan: Opening up a new era for the advancement of science. Japan: Global Perspectives Cabinet Office. Retrieved from https://www8.cao.go.jp/cstp/sonota/openscience/150330 openscience en1.pdf

G8 UK. (2013). G8 Science Ministers Statement London UK, 12 June 2013. Retrieved from https:// assets.publishing.service.gov.uk/government/uploads/system/uploads/attachment data/ file/206801/G8 Science Meeting Statement 12 June 2013.pdf

Hood, L. \& Rowen, L. (2013). The Human Genome Project: big science transforms biology and medicine. Genome Medicine, 5(79). doi: 10.1186/gm483

Houghton, J., Rasmussen, B., Sheehan, P., Oppenheim, C., Morris, A., Creaser, C. et al. (2009). Economic implications of Alternative Scholarly Publishing Models: Exploring the Costs and Benefits. Australia: Victoria University. Retrieved from https://pdfs.semanticscholar.org/45dd/ cb9ebb9c8505a4ac86718734dda3311f91d8.pdf

Li, J. \& Zhang, L. (2019). Open research data policies and practices in China. Retrieved from https:// sites.nationalacademies.org/cs/groups/pgasite/documents/webpage/pga 182837.pdf

Markin, P. (2018). China mandates open access, promotes institutional repositories and demonstrates commitment to open science. Retrieved from https://openscience.com/china-mandates-openaccess-promotes-institutional-repositories-and-demonstrates-commitment-to-open-science/

Max-Planck-Gesellschaft. (2019). Berlin Declaration. Retrieved from https://openaccess.mpg.de/BerlinDeclaration

Mizera, K. (2013). New open access policy in Australia. Retrieved from https://openscience.com/newopen-access-policy-in-australia/

National Institutes of Health. (2003). NIH Data Sharing Policy and Implementation Guidance. National Institutes of Health. Retrieved from https://grants.nih.gov/grants/policy/data sharing/ data sharing guidance.htm

Nielsen, M. (2011). Definitions of Open Sciences. Retrieved from https://lists.okfn.org/pipermail/openscience/2011-July/000907.html

Nielsen, M. (2012). Reinventing Discovery: The New Era of Networked Science. Princeton University Press.

Noorden, R.V. (2013). White House announces new US open-access policy. Retrieved from http:// blogs.nature.com/news/2013/02/us-white-house-announces-open-access-policy.html

Ooi, L.P. (2017). Moving to higher ground - from open access to open science in Asia. Retrieved from https://www.coar-repositories.org/files/Asia-OA-Meeting-2017 Singapore-Country-Update.pdf

OSF. (2019). OSF Home. Retrieved from https://osf.io/

Peking University Open Research Data. (2019). Peking University Open Research Data Platform. Retrieved from https://opendata.pku.edu.cn/

Polymath Projects. (2019). The Polymath Blog. Retrieved from http://polymathprojects.org/

Prinz, F., Schlange, T. \& Asadullah, K. (2011). Believe it or not: how much can we rely on published data on potential drug targets? Nature Reviews Drug Discovery, 10(9), 712. doi: 10.1038/ $\operatorname{nrd3439-c1.~}$

Ramjoué, C. (2015). Towards Open Science: The vision of the European Commission. Information Services \& Use, 35(3), 167-170. Doi: 10.3233/ISU-150777 
Research Center for Open Science and Data Platform. (2019). Policy developments on open science in Japan. Retrieved from https://rcos.nii.ac.jp/en/openscience/internal/

UK Research \& Innovation. (2016). Concordat on open research data. Retrieved from https:// www.ukri.org/files/legacy/documents/concordatonopenresearchdata-pdf/

UNESCO. (2017). Global Open Access Portal: Singapore. Retrieved from http://www.unesco.org/new/ en/communication-and-information/portals-and-platforms/goap/access-by-region/asia-and-thepacific/singapore/

Vignoli, M., Lujan, C., Jans, K., Dams, Y. \& Pipatti, P. (2014). YEAR Consultation on Science 2.0. Young European Associated Researchers. Retrieved from https://www.researchgate.net/profile/ Alexis Sevault/publication/277611055 YEAR Consultation on Science 20/ links/556ebb5608aeccd7773f749d/YEAR-Consultation-on-Science-20.pdf

Zenodo. (2019). Zenodo. Retrieved from https://zenodo.org

\section{For Further Reading:}

Budapest Open Access Initiative. (n.d.). Budapest Open Access Initiative. Retrieved from http:// www.budapestopenaccessinitiative.org/

Chesbrough, H. (2015). From Open Science to Open Innovation. Science | Business Publishing. Retrieved from https://www.fosteropenscience.eu/sites/default/files/pdf/1798.pdf

National Institutes of Health. (n.d.). NIH Office of Science Policy. Retrieved from https://gds.nih.gov/

Organisation for Economic Co-operation and Development. (n.d.). Open Science. Retrieved from http:// www.oecd.org/science/inno/open-science.htm

Yozwiak, N.L., Schaffner, S.F. \& Sabeti, P.C. (2015). Data sharing: Make outbreak research open access. Nature, 518(7540), 477-479. doi: 10.1038/518477a. 